\title{
IMPACTO SOCIOECONÔMICO DECORRENTE DA IMPLEMENTAÇAO DA RESERVA FLORESTAL LEGAL: UM ESTUDO DE CASO
}

\author{
Alessandro Vinicios Schneider*, Roberto Rochadelli**, Renato de Moraes Bonilha*** \\ *Mestrando em Engenharia Florestal, UFPR - schneideravs@ig.com.br \\ **Eng. Florestal, Dr., Depto. de Economia Rural e Extensão da UFPR - nashtell@floresta.ufpr.br \\ ***Graduando em Engenharia Florestal, UFPR - bonilha@floresta.ufpr.br
}

Recebido para publicação: 25/08/2005 - Aceito para publicação: 01/12/2005

\begin{abstract}
Resumo
Impacto socioeconômico decorrente da implementação da Reserva Florestal Legal: um estudo de caso. Esse estudo tem como objetivo geral determinar qual vai ser o impacto financeiro na arrecadação municipal com a implementação da reserva legal florestal nas propriedades rurais no município de Palotina, oeste do Estado do Paraná. Os dados coletados foram disponibilizados pelos órgãos competentes do município de Palotina. Os dados referentes à área plantada e produtividade média das diversas culturas, as de verão e as de inverno, foram obtidos na EMATER-Palotina, no ano de 2004. Os dados referentes aos tributos que incidem na produção foram obtidos na Secretária Municipal de Agricultura. Os tributos federais representam 2,3 \% da produção bruta retida na fonte. Os tributos municipais não são retidos na fonte (estimou-se o valor destes em $12 \%$, decorrentes da movimentação da riqueza em papel moeda gerada pela produção de grãos na economia municipal). A implementação da reserva florestal legal no município de Palotina deverá acarretar uma redução de 16,2 \% na área plantada. Ocorrerá uma redução na produção total e, por conseqüência, uma redução na receita bruta dos produtores de grãos. Ocorrerá uma redução nos tributos federais e municipais que incidem na produção de grãos. O montante total dessa redução de arrecadação dos tributos federais e municipais pode chegar a R\$3.423.622,01 por ano, o que representa aproximadamente $20 \%$ da arrecadação total do município.

Palavras-chave: Legislação florestal; política florestal; reserva legal.
\end{abstract}

\begin{abstract}
Socioeconomic impact decurrent of implementation of the Legal Forest Reserve: a case study. The general objective of this study is to determine the financial impact of implementation of the legal forest reserve in the municipality of Palotina, located in the western region of the Parana State, on the tax collection. The collected data have been made available by the competent agencies of the city of Palotina. The data referring to the planted area and average productivity of the several cultures, summer and winter cultures, had been gotten in the Company of Technical Assistance and Rural Extension (EMATER) - Palotina in the year of 2004. The data referring to the tributes related to the production had been gotten in the Municipal Secretary of Agriculture. The federal tributes represent $2,3 \%$ of the gross production retained at the source. The municipal tributes are not retained at the source, they are estimated in $12 \%$ decurrent of the wealth movement in paper currency generated by the production of grains in the municipal economy. The implementation of the legal forest reserve in the city of Palotina will bring a reduction of $16,2 \%$ over the planted area. There will be a reduction in the total production and consequently a reduction in the gross revenue of the grain producers. It will also happen a reduction in the collection of the federal and municipal tributes that incur over the production of grains. The total sum of this reduction can take the amount of R $\$ 3.423 .622,01$ per year, which represents $20 \%$ of the total collection of the municipality approximately.

Keywords: Forest legislation; forest politics; legal reserve.
\end{abstract}

\section{INTRODUÇÃO}

As relações do homem com a natureza são tão antigas quanto a própria existência da humanidade. As características dessas relações, entretanto, se alteraram significativamente com o passar 
do tempo, condicionadas pelo processo de desenvolvimento a que o homem sempre esteve sujeito. No princípio, a interferência do homem nos ecossistemas era mínima, mas, com o crescimento da população humana e conseqüentemente o processo de urbanização, ocorreram transformações drásticas nos ecossistemas que alteraram profundamente o equilíbrio da biosfera.

A racionalização da ocupação, a interferência no espaço físico disponível e o interesse de crescimento econômico têm exigido, cada vez mais, um desenvolvimento sustentável, ou seja, um processo sistêmico mediante o qual uma economia consegue simultaneamente crescer, reduzir desigualdades sociais e preservar o meio ambiente.

Uma definição de sustentabilidade não pode ficar restrita ao aspecto puramente ambiental e das políticas ambientais. Ela busca pensar o aspecto ecológico, com a relevância que lhe é devida, no contexto das estruturas sociais, econômicas e políticas. Trata-se, de fato, de pensar de maneira integrada o futuro de cada país e da humanidade como um todo, mesmo porque a busca da sustentabilidade ecológica deve ser consistente com a de outras formas de sustentabilidade, incluindo a sustentabilidade política (legitimidade das instituições e dos canais de participação), econômica (eficiência na produção/distribuição e realismo orçamentário) e social (melhoria crescente da qualidade de vida e das oportunidades de auto-realização dos indivíduos e comunidades). A confluência desse conjunto de sustentabilidade representa a busca por um modelo de desenvolvimento, na verdade um modelo de sociedade, que seja sustentável no sentido pleno da palavra.

Em outras palavras, a sustentabilidade não é nem deve ser concebida como se resumindo tão somente à base física do processo de crescimento e ter como objetivo apenas conservar o estoque de recursos naturais incorporados às atividades produtivas. A defesa da sustentabilidade não pode mais se limitar a surfar nas ondas de um ambientalismo superficial, ainda que esse seja um passo e uma etapa necessária antes de mergulhos mais profundos no conhecimento e na experiência das várias ecologias.

Todo e qualquer desenvolvimento sustentável depende da ação humana prudente e responsável, baseada em conhecimentos e sabedorias que reduzem os riscos de provocar impactos que prejudiquem a si própria.

\section{Objetivo}

Esse estudo tem como objetivo determinar o impacto financeiro na arrecadação municipal com a implementação da reserva legal florestal nas propriedades rurais no município de Palotina, oeste do Estado do Paraná.

\section{REVISÃO BIBLIOGRÁFICA}

A preocupação em preservar parte das matas nas propriedades rurais é bem antiga em nosso país. Já estava presente na época do Brasil Colônia, quando a escassez de madeira adequada para a construção das embarcações da frota portuguesa levou a Coroa a expedir as cartas régias, que declaravam de sua propriedade toda a madeira naval, denominada como "madeira de lei" (Dean,1996, p.151), nome ainda utilizado para designar as madeiras nobres em nosso país.

Porém, a iniciativa de criação de um Código Florestal só surgiu por volta de 1920, quando o presidente Epitácio Pessoa formou uma subcomissão para elaborar o anteprojeto do futuro Código Florestal. Em 1934, por fim, o projeto foi transformado no Decreto $n^{\circ} 23.793$ que, com o passar do tempo, ficou conhecido como o Código Florestal de 34. Dentre as inúmeras inovações que esse Código trouxe, a mais ousada foi a que criou o limite do direito de uso da propriedade, a chamada "quarta parte" (id., p. 75), ou seja, a reserva obrigatória de vinte e cinco por cento de vegetação nativa de cada propriedade rural. Desde o início, essa medida foi considerada pelos fazendeiros e madeireiros um sacrifício ao direito de propriedade e uma restrição grave ao uso economicamente viável do imóvel rural (CNA, 1998, $\mathrm{n}^{\mathrm{o}}$ 137).

A denominação de reserva legal veio a partir da Lei 7.803, de 18 de julho de 1989 , que introduziu, também, a exigência de averbação ou registro da reserva legal à margem da inscrição da matrícula do imóvel, sendo vedada "a alteração de sua destinação, nos casos de transmissão, a qualquer título, ou desmembramento da área” (Art. $16 \S 2^{\circ}$ ). Desde o início, o Código Florestal vem sofrendo inúmeras alterações, por meio de leis e medidas provisórias, que demonstram a dificuldade dos legisladores em conciliar os interesses dos diversos atores envolvidos no assunto. 
Em relação à reserva legal, contesta-se o limite do direito de uso da propriedade e os percentuais de $20 \%, 35 \%$ e $80 \%$ de área do imóvel destinada à reserva legal, de acordo com a região e a fisionomia vegetal (MP no 1956-50/00, Art. 16, inciso II).

As mais recentes modificações do Código Florestal ocorreram em maio de 2000 e foram acompanhadas por vários segmentos da sociedade civil mobilizada, organizações não-governamentais ambientalistas e entidades representantes dos agricultores, alcançando ampla repercussão na mídia de todo o país.

Dentre os pontos contemplados na Medida Provisória $n^{\circ} 1956-50 / 00$, destaca-se o chamado mecanismo de compensação da reserva legal, que oferece ao produtor rural que não dispõe dessa área em sua propriedade a alternativa de compensá-la em outra região, equivalente em extensão e relevância ecológica, na mesma microbacia hidrográfica (Art. 44, inciso II). Outro destaque dessa MP é a definição, pela primeira vez, da função da reserva legal como área de conservação da biodiversidade, retirando o caráter utilitarista que acompanhou a reserva legal desde os primórdios de sua criação, sendo assim definida como "área localizada no interior de uma propriedade ou posse rural, excetuada a de preservação permanente, necessária ao uso sustentável dos recursos naturais, à conservação e reabilitação dos processos ecológicos, à conservação da biodiversidade e ao abrigo e proteção de fauna e flora nativa".

Enquanto as discussões sobre a reserva legal continuam no Congresso, nas assembléias e nas câmaras, sem que se chegue a um consenso sobre qual vai ser o seu destino, a conservação dos remanescentes de vegetação nativa nas propriedades continuará a depender, principalmente, da decisão dos produtores rurais em proteger essas áreas ou não.

Após três décadas de implantação, o padrão convencional de agricultura tem se mostrado insustentável, não só pelo aumento da pobreza e o aprofundamento das desigualdades, mas também pelos impactos ambientais negativos causados pelo desmatamento continuado, pela redução dos padrões de diversidade preexistentes, pela intensa degradação dos solos agrícolas e contaminação química dos recursos naturais, entre tantos outros impactos.

\section{MATERIAIS E MÉTODOS}

O Município de Palotina localiza-se na Microrregião Extremo Oeste Paranaense (288-IBGE), no Estado do Paraná, região Sul do Brasil. O Município possui uma área de 64.743 ha $\left(647,430 \mathrm{~km}^{2}\right)$ e uma população de 27.283 habitantes, o que representa uma densidade demográfica de 42,14 habitantes por quilômetro quadrado. A cobertura vegetal original foi totalmente devastada, sendo substituída por extensas áreas cultivadas. A parcela remanescente de floresta latifoliada soma hoje apenas 3,8\% da área do município. Palotina conta com uma reserva ecológica denominada Reserva Biológica Estadual de São Camilo, criada pelo Decreto $\mathrm{n}^{\mathrm{o}}$ 6595, de 22.02.90, com área de 385,34 ha (fonte: Comarca de Palotina/março de 2000).

Os dados coletados foram disponibilizados pelos órgãos competentes do município de Palotina. Os dados referentes à área plantada e produtividade média das diversas culturas, as de verão e as de inverno, foram obtidos na EMATER-Palotina, no ano de 2004. Os dados referentes aos tributos que incidem na produção foram obtidos na Secretária Municipal de Agricultura. Os tributos federais representam $2,3 \%$ da produção bruta retida na fonte. Os tributos municipais não são retidos na fonte (tais tributos foram estimados em $12 \%$, decorrentes da movimentação da riqueza em papel moeda gerada pela produção de grãos na economia municipal). O preço por saca utilizado foi a média dos últimos cinco meses do ano de 2004, comercializados no município, sendo R\$ 19,00 para milho no verão, R\$ 35,00 para soja, $\mathrm{R} \$ 16,00$ para milho no inverno e $\mathrm{R} \$ 28,00$ para o trigo.

Conforme EMATER, no município de Palotina, região oeste do Paraná, a produtividade média do município na cultura de milho no verão é de 7.450 quilos por ha, com uma área total plantada em média/ano de 3.000 ha; a de soja é de 3.300 quilos por ha, com uma área plantada em média/ano de 42.000 ha. O milho plantado no inverno apresenta produtividade média de 5.800 quilos por ha $\mathrm{e}$ representa uma área plantada de 30.400 ha/ano do total; a produtividade de trigo é de 2.500 quilos por ha, com uma área plantada em média/ano de 11.000 ha. 


\section{RESULTADOS E DISCUSSÕES}

Com a implementação da reserva florestal legal nas propriedades rurais em Palotina, ocorrerá uma redução de aproximadamente $16,2 \%$ na área plantada no município, conforme dados levantados na Secretaria Municipal de Planejamento de Palotina. Devido a essa redução da área plantada, ocorrerá uma redução na receita bruta dos produtores de grãos que influenciará diretamente na arrecadação dos tributos municipais e federais referentes a essas atividades (Tabela 1).

Tabela 1. Diferença de receita bruta com a implementação da reserva legal no município de Palotina (PR).

Table 1. Gross income difference with the implementation of the legal reserve in the municipality of Palotina.

\begin{tabular}{lccc}
\hline Cultura & $\begin{array}{c}\text { Receita Bruta (Sem } \\
\text { Reserva Legal) }\end{array}$ & $\begin{array}{c}\text { Receita Bruta (Com Reserva } \\
\text { Legal) } \\
\text { (R\$) }\end{array}$ & $\begin{array}{c}\text { Diferença com } \\
\text { Implementação da Reserva } \\
\text { Legal (R\$) }\end{array}$ \\
\hline Milho (verão) & 7.077 .120 .00 & 5.930 .626 .56 & 1.146 .493 .44 \\
Soja (verão) & 80.850 .000 .00 & 67.752 .300 .00 & 13.097 .700 .00 \\
Milho (inverno) & 47.015 .424 .00 & 39.398 .925 .28 & 7.616 .498 .72 \\
Trigo (inverno) & 12.833 .333 .24 & 10.752 .612 .64 & 2.080 .720 .60 \\
\hline
\end{tabular}

No que se refere aos tributos municipais, foi deduzido um percentual de $12 \%$ sobre a diferença de arrecadação municipal com a implementação da reserva legal, representando um montante anual de R\$ 2.872.969,52, referentes aos cultivos das culturas. Os tributos federais (FUNRURAL) foram deduzidos a partir de um percentual de 2,3\%, representando um montante anual de R\$550.652,49. A soma da arrecadação dos tributos municipais e federais totalizou R\$ 3.423.622,01 durante o decorrer de um ano. No que se refere à redução mensal dos tributos, ela totaliza um montante de $\mathrm{R} \$ 285.301,83$, representando aproximadamente $20 \%$ da arrecadação total mensal do município, ou seja, uma redução significativa referente aos cultivos de milho no verão, soja, milho no inverno e trigo (Tabela 2).

Tabela 2. Redução tributária total com a implementação da reserva legal no município de Palotina.

Table 2. Total tributary reduction with the implementation of the legal reserve in the municipality of Palotina.

\begin{tabular}{lccc}
\hline Cultura & $\begin{array}{c}\text { Total em R\$/ano em } \\
\text { tributos federais }\end{array}$ & $\begin{array}{c}\text { Total em R\$/ano em tributos } \\
\text { municipais }\end{array}$ & $\begin{array}{c}\text { Total em tributos municipais e } \\
\text { federais (R\$/ano) }\end{array}$ \\
\hline Milho (verão) & 26.369 .35 & 137.579 .21 & 163.948 .56 \\
Soja (verão) & 301.247 .10 & 1.571 .724 .00 & 1.872 .971 .10 \\
Milho (inverno) & 175.179 .47 & 913.979 .84 & 1.089 .159 .31 \\
Trigo (inverno) & 47.856 .57 & 249.686 .47 & 297.543 .04 \\
\hline Total & 550.652 .49 & 2.872 .969 .52 & 3.423 .622 .01 \\
\hline
\end{tabular}

\section{CONCLUSÕES}

- A implementação da reserva florestal legal no município de Palotina deverá acarretar uma redução de $16,2 \%$ na área plantada.

- Ocorrerá uma redução na produção total e, por conseqüência, uma redução na receita bruta dos produtores de grãos.

- Ocorrerá uma redução nos tributos federais e municipais que incidem na produção de grãos.

- O montante total dessa redução de arrecadação dos tributos federais e municipais pode chegar a $\mathrm{R} \$ 3.423 .622,01$ por ano, o que representa aproximadamente $20 \%$ da arrecadação total do município. 


\section{REFERÊNCIAS}

BRASIL. Decreto n. 23.793, de 23 de janeiro de 1934. Aprova o Código Florestal. Diário Oficial da República Federativa do Brasil, Rio de Janeiro, RJ, 09 fev. 1934.

BRASIL. Lei nr. 7.803, de 18 de julho de 1989. Altera a redação da Lei no ${ }^{\circ} .4771$, de 15 de setembro de 1965, e revoga as Leis $\mathrm{n}^{\text {os }}$.6.535, de 15 de junho de 1978, de 15 de junho de 1978 e 7.511 , de 7 de julho de 1986. Diário Oficial da República Federativa do Brasil, Brasília, DF, 20 jul. 1989.

BRASIL. Lei n. 4.771, de 15 de setembro de 1965. Institui o novo Código Florestal, bem como altera o art. 10 da Lei n. 9.393, de 19 de dezembro de 1996, que dispõe sobre o imposto sobre a propriedade territorial rural - ITR, e dá outras providências. Diário Oficial da República Federativa do Brasil, Brasília, DF, 16 set. 1965.

BRASIL. Medida Provisória n. 1.956/50, de 27 de maio de 2000. Altera os arts. $1^{\circ}, 4^{\circ}$. $14^{\circ}$., $16^{\circ}$. e 44 , e acresce dispositivos à Lei n. 4.771, de 15 de setembro de 1965, que institui o Código Florestal, bem como altera o art. $10^{\circ}$. da Lei n. 9.393, de 19 de dezembro de 1996, que dispões sobre o imposto sobre a propriedade territorial rural - ITR e dá outras providências. Diário Oficial da República Federativa do Brasil, Brasília, DF, 28 maio 2000.

DEAN, W. A ferro e fogo: a história e a devastação da Mata Atlântica brasileira. São Paulo: Companhia das Letras, 1996.

EMATER.Diagnóstico Ambiental do Município de Palotina-Pr. 1986. Não publicado. 